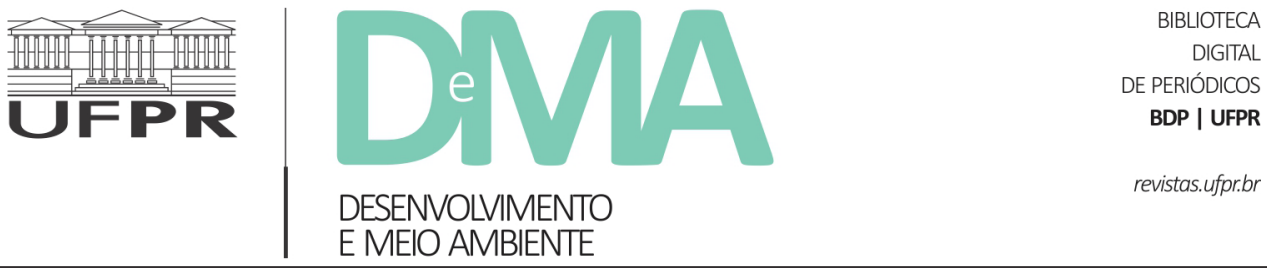

\title{
A sustentabilidade no gerenciamento de resíduos sólidos urbanos: um estudo em restaurantes no município de Irati, PR
}

\section{Sustainability urban solid waste management: a study on restaurants in Irati City, PR}

\author{
Flavia MASSUGA ${ }^{1 *}$, Sérgio Luis Dias DOLIVEIRA ${ }^{1}$, Carlos Alberto Marçal GONZAGA ${ }^{1}$, Simone SOARES \\ ${ }^{1}$ Universidade Estadual do Centro Oeste (UNICENTRO), Irati, Paraná, Brasil. \\ *E-mail de contato: flavia.massuga@gmail.com
}

Artigo recebido em 8 de fevereiro de 2020, versão final aceita em 18 de abril de 2021, publicado em 15 de dezembro de 2021.

RESUMO: Mudanças nos comportamentos alimentares associadas ao crescimento da alimentação fora do lar refletem o aumento da preocupação com o gerenciamento correto de resíduos sólidos gerados em restaurantes com o propósito de mitigar problemas ambientais, sociais e econômicos. A fim de elucidar essa questão, este estudo teve como objetivo principal investigar o gerenciamento e o descarte final de resíduos sólidos em restaurantes no município de Irati, PR, e sua relação com a sustentabilidade. Para tanto, optou-se pela realização de uma pesquisa descritiva com abordagem mista, conduzida por meio de estudos de casos múltiplos em dez restaurantes selecionados intencionalmente. A operacionalização ocorreu nos meses de setembro e outubro de 2019, por meio de entrevistas com os gestores, aplicação de questionários aos colaboradores e observações in loco. Além disso, foram utilizados como apoio à investigação documentos legais e regulamentares pertinentes à temática dos resíduos sólidos. Os resultados apontam a diversidade de resíduos sólidos gerados nos restaurantes e destacam a presença do óleo de cozinha e lâmpadas, sendo resíduos perigosos. Denotou-se uma gestão deficiente dos resíduos sólidos, considerando a existência de inconformidades relacionadas às fases de gerenciamento, bem como a ausência de PGRS. Além disso, são evidenciadas poucas ações vinculadas ao cumprimento das leis e regulamentos relacionados à temática, o que pode ser identificado, por exemplo, na não responsabilização pela destinação de todos os resíduos gerados e na prática limitada da logística reversa. Considerando a discussão sob a perspectiva da sustentabilidade, destacam-se pontos positivos e negativos nos três pilares, ambiental, econômico e social e denota-se uma não visualização, por parte dos restaurantes, de práticas sustentáveis como oportunidade de negócios. Deficiências são justificadas pela falta de informações, bem como pelo baixo poder de enforcement das regulamentações existentes, sendo necessárias políticas públicas direcionadas.

Palavras-chave: resíduos sólidos comerciais; gestão de resíduos; restaurantes; sustentabilidade. 
ABSTRACT: Changes in eating behaviors associated with the growth of food outside the home reflect the increased concern with the correct management of solid waste generated in restaurants to mitigate environmental, social, and economic problems. To elucidate this issue, this study aimed to investigate the administration and final disposal of solid waste in restaurants in the municipality of Irati, PR, and its impacts concerning sustainability. To this end, it was decided to conduct descriptive research with a mixed approach, conducted through multiple case studies in ten restaurants selected intentionally. Operationalization took place in September and October 2019 through interviews with managers, questionnaires to employees, and observations on the spot. In addition, legal and regulatory documents relevant to the solid waste theme were used to support research. The results show the diversity of solid waste generated in restaurants and highlight the cooking oil and lamps presence, being as hazardous waste. Deficient solid waste management was noted, considering the existence of nonconformities related to the management phases, as well as the absence of the PGRS. In addition, there are few actions linked to compliance with laws and regulations related to the theme, which can be identified, for example, in the non-responsibility for the destination of all the waste generated and in the limited practice of reverse logistics. Considering the discussion from the perspective of sustainability, there are positive and negative points in the three pillars, environmental, economic, and social, and there is a failure of restaurants to see sustainable practices as a business opportunity. Deficiencies are justified by the lack of information as well as the low enforcement power of the existing regulations, requiring targeted public policies.

Keywords: commercial solid waste; waste management; restaurants; sustainability.

\section{Introdução}

O desenvolvimento nas últimas décadas, representado pelo crescimento econômico fundamentado na exploração intensiva dos recursos naturais, resultou, além de problemas de ordem socioeconômicos, em impactos negativos ao ambiente, colocando em risco a sobrevivência dos ecossistemas (Klarin, 2018). O aumento da percepção das consequências das ações antrópicas sobre o meio, como alterações climáticas globais, altos índices de poluição, dizimação de espécies, fome e pobreza e outros efeitos negativos, tem alertado sobre a necessidade de um modo sustentável de vida em todos os segmentos (Boff, 2017).

A sustentabilidade, definida com base na inter-relação de três pilares (Elkington, 1997), induz a uma nova forma de atuação interdisciplinar que considera, além do desempenho econômico, a performance nos aspectos ambiental e social. Ela visa garantir níveis de acesso a recursos naturais escassos a todos os cidadãos e qualidade de vida para atuais e futuras gerações (Altenburg \& Pegels, 2012).

Entre os aspectos relevantes das atividades de sustentabilidade, destacam-se aqueles vinculados ao gerenciamento de resíduos sólidos e efluentes. A temática tornou-se eminente como um problema pungente e generalizado, devido ao aumento na diversidade e geração de resíduos, provocado por fatores como rápida industrialização, crescimento populacional e alterações nos padrões de consumo, aparentes na maioria dos países (Potdar et al., 2016; Abdel-Shafy \& Mansour, 2018).

De acordo com Kaza et al. (2018), a previsão mundial para 2050 é de que sejam produzidos cerca de 3,4 bilhões de toneladas de resíduos sólidos, uma tendência de geração a um nível maior do que a taxa de urbanização. Considerando dados nacionais, em 2018, foram gerados no Brasil 79 milhões de toneladas de resíduos sólidos, sendo que 40,5\% foram despejados em locais ausentes de controles 
sobre danos ambientais e degradações (Associação Brasileira de Limpeza Pública e Resíduos Especiais [ABRELPE], 2020).

Diante desse contexto, se a intensidade de exploração continuar, os pontos de inflexão ambiental podem provocar desequilíbrios ecossistêmicos insustentáveis (Altenburg \& Pegels, 2012; Alves, 2019). Desta forma, torna-se necessária a gestão adequada e sustentável dos resíduos sólidos realizada por medidas e técnicas visando a eliminação dos seus efeitos nocivos, tornando-os úteis ao homem, com retornos positivos à saúde humana e ao meio ambiente (Okwesili et al., 2016).

Considerando o setor empresarial, os restaurantes correspondem a estabelecimentos comerciais que contribuem significativamente para a produção de resíduos sólidos, cuja gestão é complexa. Os resíduos gerados por esses estabelecimentos podem ser compreendidos como resíduos alimentares, ou seja, aqueles resultantes do processamento, cozimento, distribuição, produção e consumo de alimentos (Abdel-Shafy \& Mansour, 2018). A maior parte de resíduos sólidos gerados é proveniente de restos de comida, os quais relacionam-se ao complexo problema social da segurança alimentar e, ao mesmo tempo, podem causar danos ambientais consideráveis (Chen, 2019). A segunda maior proporção é de produtos e materiais de embalagem (Landry et al., 2018) que, da mesma forma, dado seu mau gerenciamento, são responsáveis por provocar impactos ambientais negativos, tais como contaminação dos recursos hídricos, destruição da estética e problemas de saúde e segurança (Ibrahim \& Mohamed, 2016; Okwesili et al., 2016).

Devido ao descarte de grande quantidade, o gerenciamento, reutilização, processamento ou destinação final adequada e sustentável dos resíduos sólidos nesse setor merece atenção, especialmente considerando a prática da alimentação fora do lar, que cresce a passos largos. Estudos como de Corrêa \& Lange (2011), Peruchin et al. (2013), Carneiro (2014), Alves \& Ueno (2015), Pistorello et al. (2015) e De Clercq et al. (2016) buscaram investigar a gestão dos resíduos sólidos no contexto específico dos restaurantes, com ênfase especial nos resíduos sólidos orgânicos.

Com o intuito de preencher lacunas ainda existentes e, considerando a importância dos avanços das pesquisas na área, associadas às noções de sustentabilidade, o presente estudo teve como objetivo principal investigar o gerenciamento e o descarte final de resíduos sólidos em restaurantes no município de Irati, PR, e sua relação com a sustentabilidade. Considerando o contexto específico abrangido pela pesquisa, cabe ressaltar que a coleta seletiva é de responsabilidade da prefeitura, a qual terceiriza a coleta dos resíduos orgânicos e prioriza a atuação de coletivos organizados de trabalhadores nos moldes de cooperativa e associação, conforme prescreve a Lei Federal n. 13.305/2010 (Brasil, 2010).

A fim de atender a esse propósito central, foram identificadas as tipologias e classificações dos resíduos sólidos produzidos nos estabelecimentos; descritos os processos de gerenciamento e destinação final dos resíduos sólidos gerados; avaliada a conformidade das práticas com as regulamentações e legislações pertinentes, essencialmente considerando a Política Nacional dos Resíduos Sólidos (PNRS); e descrita a relação do gerenciamento atual adotado com a sustentabilidade. 


\section{A sustentabilidade e o gerenciamento de resíduos sólidos}

Com o advento da revolução industrial, pautada em uma ordem capitalista de produção, o desenvolvimento permaneceu por um bom tempo intrinsicamente relacionado às noções econômicas de crescimento. No geral, a relação entre as pessoas e o ambiente foi idealizada como a conquista da humanidade sobre a natureza, baseada em sua intensiva exploração. A crença no controle de todos os obstáculos, inclusive os ambientais por meio da tecnologia e conhecimento, também prevalecia (Hopwood et al., 2005).

A consciência planetária e ecológica e a inversão do pensamento de domínio absoluto sobre a natureza começaram a ganhar forma em meados do século XX, fruto da percepção de uma crise ambiental global, causada pelos impactos da intervenção do homem na natureza, que mais tarde fez emergir o conceito de sustentabilidade (Nascimento, 2012). Apesar das diversas abordagens e confusões conceituais observa-se um consenso entre autores no que tange à compreensão da sustentabilidade como constituída por três dimensões inter-relacionadas: econômica, ambiental e social, a qual surgiu a partir da definição disseminada por John Elkington (1997), conhecida como Triple Botton Line (TBL). A dimensão ambiental da sustentabilidade, relaciona-se ao capital em seu sentido mais amplo, visando limitar a atividade humana conforme a capacidade de suporte dos ecossistemas (Klarin, 2018). O pilar social, concentra-se no bem-estar social e supõe que todos os cidadãos tenham o mínimo necessário para desfrutar uma vida digna (Olawumi \& Chan, 2018). Por sua vez, o pilar econômico abrange a economia formal e informal que oportunizam emprego e refletem na renda e padrão de vida dos indivíduos e considera o uso eficiente dos recursos (Claro et al., 2008; Olawumi \& Chan, 2018).

Com o crescente discurso sobre a sustentabilidade e desenvolvimento sustentável, as empresas, ora vistas como uma das causas raízes das crises ambientas, ora como uma das fontes potenciais de soluções sustentáveis (Zollo et al., 2013), foram pressionadas a reavaliar suas prioridades e finalidades. Isso levou ao reposicionamento de estratégias a fim de atender não só às necessidades da organização, como também de seus stakeholders no que tange à preservação dos recursos e demandas sociais. Ao implementar práticas sustentáveis, as organizações, além de contribuírem para a sociedade e o meio ambiente, obtêm retornos positivos ao seu próprio negócio conquistando vantagens competitivas (Lloret, 2016). No entanto, parte das organizações ainda não visualizam a sustentabilidade como oportunidade, e muitos problemas estão presentes na prática, como a falta de orientação estratégica (Nidomulo et al., 2009).

Dentre os aspectos relevantes que abrangem as discussões sobre sustentabilidade e o setor empresarial, destacam-se as aquelas relacionadas à gestão dos resíduos sólidos e efluentes. Devido aos impactos ambientais e sociais, o gerenciamento de resíduos torna-se uma questão fundamental para a qualidade de vida das atuais e futuras gerações. Ademais, passa a ser uma oportunidade para as organizações, considerando seus grandes volumes gerados e sua capacidade de influência nos padrões de produção e consumo (Abdel-Shafy \& Mansour, 2018). 
O gerenciamento de resíduos é constituído basicamente pelas etapas de segregação, acondicionamento, coleta, transporte, tratamento e disposição final (Instituto Brasileiro de Administração Municipal [IBAM], 2001; Aleluia \& Ferrão, 2016). A primeira envolve a classificação e separação dos resíduos conforme suas características particulares. A fase de acondicionamento consiste na ação de acondicionar os resíduos de forma sanitariamente adequada e compatível com o tipo e quantidade de resíduos. A coleta e o transporte correspondem às fases subsequentes e referem-se ao recolhimento do resíduo acondicionado para encaminhá-lo a um eventual tratamento e à disposição final. $\mathrm{O}$ tratamento, por sua vez, relaciona-se a uma série de procedimentos que se destinam a reduzir o volume de resíduos ou seu potencial poluidor. Por fim, a disposição final, que consiste em dar um destino final adequado aos resíduos, é de importância crítica devido a sua capacidade de impactar em grande parte o meio ambiente e a saúde pública (Aleluia \& Ferrão, 2016; Potdar et al., 2016). Segundo Ibrahim \& Mohamed (2016), dentre lixões abertos, aterros controlados e aterros sanitários, apenas os aterros sanitários podem ser entendidos como adequados para a destinação final de resíduos, por possuírem medidas para evitar os riscos dos descartes.

As leis, bem como seu planejamento, implementação e revisão constante são importantes instrumentos administrativos que possibilitam o gerenciamento correto e eficaz dos resíduos sólidos (Durgekar, 2016). No Brasil, como marco regulatório dessas discussões, foi aprovada em 2 de agosto de 2010 a Lei Federal n. 12.305/2010 que instituiu a Política Nacional dos Resíduos Sólidos (PNRS), significando um expressivo avanço, considerando um histórico de gestão e disposição incorreta dos resíduos sólidos.

Além de instituir diretrizes gerais para o gerenciamento de resíduos sólidos, a lei estabelece a gestão integrada dos resíduos sólidos entre o governo federal, estados, municípios e particulares (Voss et al., 2013). O princípio de gestão compartilhada reflete na necessidade de elaboração de planos de resíduos sólidos, sendo eles, o Plano Nacional de Resíduos Sólidos; os Planos Estaduais de Resíduos Sólidos (PERS), os Planos Municipais de Gestão Integrada de Resíduos Sólidos (PMGIRS) e os Planos de Gerenciamento de Resíduos Sólidos (PGRS), para entes privados (Brasil, 2010).

Quanto à elaboração do PGRS, estão incluídos os estabelecimentos comerciais e de prestação de serviços que gerem resíduos perigosos ou que, mesmo caracterizados como não perigosos, por sua natureza, composição ou volume, não sejam equiparados aos resíduos domiciliares (Brasil, 2010). Dentre os requisitos mínimos, o plano deve conter a descrição da atividade; o diagnóstico dos resíduos gerados; ações de responsabilidade compartilhada pelo ciclo de vida dos produtos e outras medidas para sanar os passivos ambientais provocados (Voss et al., 2013).

A lei também regulamenta a logística reversa, tornando-a uma responsabilidade do gerador, importador, distribuidor, comerciante e do consumidor, estabelecer um fluxo reverso de embalagens de agrotóxicos, pilhas e baterias, pneus, óleos lubrificantes, lâmpadas fluorescentes e produtos eletrônicos e seus componentes, independentemente do sistema de limpeza urbana e do manejo dos resíduos sólidos (Voss et al., 2013). Com base nessas diretrizes, é dever dos entes federativos e 
empresas privadas elaborar e executar seu plano de gerenciamento conforme realidade e condições locais determinantes.

\section{O segmento de restaurantes e a gestão de resíduos sólidos}

A grande concentração de pessoas em centros urbanos, a maior participação da mulher no mercado de trabalho, o aumento do poder aquisitivo, a crescente expectativa de vida e as transformações nos hábitos e costumes da população vêm resultando em mudanças nos comportamentos alimentares, refletidos principalmente na expansão da alimentação fora do lar, com grande destaque para o nicho de restaurantes.

De acordo com a Associação Brasileira da Indústria de Alimentos (ABIA, 2018), os empreendimentos de food service totalizam 1,3 milhão de pontos de vendas no Brasil, refletindo em um faturamento representativo, possibilitados pela destinação de cerca de $34,5 \%$ da renda familiar com gastos nesse setor. Sua expansão é evidente, visto que, nos últimos 10 anos, o crescimento da alimentação fora do lar figurou em torno de 246,2\%.

Devido à sua representatividade e amplitude no contexto nacional, elevada também é a produção de resíduos sólidos pelos estabelecimentos de food service. Essa constatação pode ser confirmada pelo estudo de Landry et al. (2018), o qual evidenciou que uma maior densidade no número de restaurantes resulta em maior produção de resíduos sólidos urbanos, se comparados a locais com números maiores de lojas que vendem alimentos para consumo em casa. Segundo Carneiro (2014), na realidade operacional dos restaurantes, a produção de resíduos sólidos acontece desde o recebimento dos alimentos, passando pelas etapas de pré-preparo e preparo até a distribuição final ao consumidor.

Os resíduos sólidos provenientes de restaurantes podem ser divididos em dois segmentos: resíduos alimentares úmidos, que incluem sobras de clientes e sobras de preparação; e resíduos secos, abrangendo, em grande parte, materiais recicláveis gerados nas etapas de produção e consumo (De Clercq et al., 2016). A complexidade dos resíduos sólidos gerados no segmento de restaurantes é ainda destacada por Abdel-Shafy \& Mansour (2018). De acordo com os autores, os resíduos são geralmente úmidos, colocados de forma aleatória e, às vezes, encontram-se misturados a materiais recicláveis.

Considerando especificamente os resíduos orgânicos, conforme estimativas do World Resources Institute (WRI), o Brasil desperdiça 41 mil toneladas de alimentos por ano. Desse total, $15 \%$ corresponde ao setor de restaurantes $(\sim 6$ mil toneladas) (Associação Brasileira de Bares e Restaurantes [ABRASEL], 2018). Diversos são os impactos prejudiciais significativos provocados pelo desperdício alimentar. Do ponto de vista social, o descarte de alimentos aptos ao consumo humano resulta na perda de oportunidades para o enfrentamento da insegurança alimentar que afeta ainda cerca de 2 bilhões de pessoas no mundo (Food and Agriculture Organization of the United Nations [FAO], 2019). Impactos ambientais são observados desde a produção e processamento devido à utilização de recursos naturais até o descarte em aterros, gerando incômodo de odor e produção de Gases Efeito Estufa (GEE) e lixiviados (Thyberg \& Tonjes, 2016). Em relação à questão econômica, sobras alimentares estão relacionadas a uma significativa perda de recursos investidos na produção, 
transporte e armazenamento de alimentos (Alves \& Ueno, 2015).

Quase a totalidade do desperdício de alimentos no setor gastronômico é considerado evitável e uma grande parcela de culpa pode ser atribuída à forma de gerenciamento dos próprios estabelecimentos. De acordo com Pistorello et al. (2015), em muitas situações, o desperdício de alimentos é ocasionado devido à oferta ser maior do que o consumo, sendo necessária uma readequação no planejamento. Demais problemas de gerenciamento podem ser identificados, tais como: inexistência de PGRS, ausência de treinamento adequado aos funcionários, tratamento dos resíduos perigosos como resíduo comum, acondicionamento dos resíduos em locais inadequados, falta de lixeiras específicas e sobrecarga dos funcionários (Peruchin et al., 2013). Inconformidades em relação às condutas de separação, acondicionamento e transporte dos resíduos também são evidenciadas (Correa \& Lange, 2011), assim como questões culturais que estimulam o desperdício e contribuem com o aumento da geração de resíduos (Carneiro, 2014).

Deste modo, o gerenciamento de resíduos nos restaurantes merece atenção, especialmente dado o crescimento acelerado da alimentação fora do lar. Resíduos gerados nesse setor precisam ser processados de modo correto, a fim de mitigar problemas de poluição ambiental, questões sociais, associadas principalmente à segurança alimentar, e possibilitar maiores rendimentos econômicos. Isso envolve, dentre outros fatores, um maior controle sobre a geração dos resíduos, incorporando, por exemplo, o controle gravimétrico, o planejamento adequado dos cardápios com a implementação de medidas preventivas de geração de resíduos sólidos, a correta segregação e destinação final destes.

\section{Metodologia}

Trata-se de um estudo descritivo que busca examinar e descrever a gestão dos resíduos sólidos efetuada nos restaurantes (Pereira, 2010), tendo o município de Irati-PR como local de aplicação do estudo.

O município está localizado na região Sudeste do estado do Paraná a cerca de $150 \mathrm{~km}$ da capital Curitiba, com população estimada em 2020 de 61.088 indivíduos, fazendo parte dos 5.059 municípios no Brasil que possuem até 65.000 habitantes (Instituto Brasileiro de Geografia e Estatística [IBGE] 2020). Seu Produto Interno Bruto (PIB) per capita para o ano de referência de 2018 foi de R \$30.279,24 (IBGE, 2021a) e suas atividades econômicas estão distribuídas no setor de comércio $(45,80 \%)$; serviços $(33,12 \%)$; indústria $(12,53 \%)$; agropecuária $(4,64 \%)$ e construção civil $(3,91 \%)$ (Instituto Paranaense de Desenvolvimento Econômico e Social [IPARDES], 2019). Nesse sentido, o estudo aborda uma questão complexa enfrentada por muitas cidades brasileiras relacionada aos grandes desafios da gestão dos resíduos sólidos municipais (Potdar et al., 2016; Durgekar, 2016).

Adotando-se uma concepção filosófica pragmática que enfatiza o problema de pesquisa e utiliza de todas as abordagens disponíveis para compreensão deste, quanto à problemática, a pesquisa se classifica como mista, integrando suposições de natureza quantitativas e qualitativas (Creswell, 2010). Quanto aos procedimentos técnicos, optou-se pela realização de estudos de casos múltiplos. De acordo com Yin (2010, p. 39), o estudo de caso pode ser compreendido como "[...] uma investigação empírica que analisa um fenômeno contemporâneo 
dentro de seu contexto". Quando múltiplos, consideram-se as especificidades de cada caso, selecionados sem lógica de amostragem e analisados simultaneamente.

Considerando os procedimentos de campo, optou-se pelo uso da triangulação metodológica, que visa a analisar o objeto a partir de variados pontos de referência, os quais complementam-se na conclusão do estudo (Vergara, 2006). Para a triangulação, foram utilizados quatro instrumentos de coleta de dados, sendo: a) pesquisa documental (qualitativa); b) entrevista semiestruturada (qualitativa); c) observação não participante (qualitativa); e d) questionário aplicado aos funcionários (quantitativa).

A pesquisa documental está incluída na avaliação da conformidade das práticas de gerenciamento e descarte de resíduos sólidos a partir de instrumentos legais pertinentes ao assunto. As entrevistas foram aplicadas aos gestores dos estabelecimentos selecionados para o estudo. Especificamente, foram utilizadas entrevistas semiestruturadas, uma forma flexível que permite acrescentar novas questões pelo entrevistador no roteiro pré-estabelecido (Dawson, 2009). O roteiro foi formulado incluindo um cabeçalho com informações básicas sobre a caracterização do gestor e do empreendimento, seguida por 24 questões específicas relacionadas diretamente às práticas de gerenciamento dos resíduos sólidos gerados nos restaurantes.

O questionário teve como alvo os funcionários dos restaurantes selecionados, sendo constituído por 10 questões relacionadas ao gerenciamento e destinação final dos resíduos sólidos gerados, a fim de complementar as informações obtidas pelas entrevistas.
A observação também foi selecionada como uma das técnicas de coleta de dados. Para este estudo, foi utilizado o método de observação não participante, na qual o pesquisador presencia o fato, porém sem realizar interferência ou apresentar envolvimento com a situação (Vergara, 2006). Foram priorizadas as visitas nos locais de preparação de alimentos e de separação e acondicionamento de resíduos a fim de compreender as ações efetuadas em relação ao gerenciamento dos resíduos sólidos gerados.

Para a seleção da amostra dos restaurantes a serem investigados, utilizou-se da amostragem não probabilística intencional, definida como um método de seleção aleatória dos elementos, admitindo que estes possam, de algum modo, representar a população (Pereira, 2010). Inicialmente, para fins deste estudo, levantou-se dados sobre o universo de restaurantes passíveis de serem investigados. Com o auxílio do setor de tributação da prefeitura municipal, emitiu-se um relatório com todos os estabelecimentos, em cujos registros constava a atividade como restaurante. Para possibilitar resultados próximos da intenção de pesquisa, a busca foi restringida utilizando categorias definidas no Código Nacional de Atividades Econômicas (CNAE) (Tabela 1), excluindo-se dos resultados os Microempreendedores Individuais (MEI).

Após busca inicial, obteve-se um retorno de 43 resultados. Dado um prévio conhecimento sobre os empreendimentos listados, foram excluídos aqueles cuja atividade principal não estava voltada ao consumo de alimentos, como bares e casas de festas e outras modalidades distintas de restaurantes, como pizzarias. Além disso, foram eliminadas as categorias de fast-food visando manter apenas restaurantes full-service que oferecem serviços de 
TABELA 1 - CNAE utilizado para representação do universo de pesquisa.

\begin{tabular}{ll}
\hline \multicolumn{1}{c}{ CNAE } & \multicolumn{1}{c}{ Atividade correspondente } \\
\hline Divisão: 56 & Alimentação \\
Grupo: 56.1 & Restaurantes e outros serviços de alimentação e bebidas \\
Classe: $56.11-2$ & Restaurantes e outros estabelecimentos de serviços de alimentação e bebidas. \\
Subclasse $5611-2 / 01$ & Restaurantes e similares. \\
\hline
\end{tabular}

FONTE: IBGE (2021b).

buffet e/ou à la carte. Considerando os critérios de exclusão, obteve-se um total de 27 restaurantes, dos quais 10 foram selecionados intencionalmente devido a fatores de acessibilidade e maior fluxo de pessoas. Da mesma forma, para seleção da amostra de funcionários, contou-se com a ajuda do gestor do empreendimento na indicação de dois colaboradores por empresa, pertencentes ao setor de preparação de alimentos, estando diretamente vinculados aos processos de geração e gerenciamento de resíduos. Os dados foram coletados nos meses de setembro e outubro de 2019, conforme disponibilidade indicada pelos restaurantes.

Neste estudo, para a análise dos dados qualitativos de pesquisa, optou-se pelo método de análise de conteúdo, um conjunto de técnicas que visa, por meio de procedimentos sistemáticos, descrever os conteúdos de determinadas mensagens e obter conhecimentos relacionados a elas (Bardin, 2011). No que concerne aos dados quantitativos, foi empregada a estatística descritiva univariada, cuja análise é realizada a partir de variáveis simples sem referência a outras variáveis, por meio de medidas de tendência central (Sahu, 2013). Cabe ainda destacar que nos resultados os restaurantes foram apresentados como Rest. 1, Rest. 2, [...], e Rest. 10, conforme ordem de investigação.

\section{Resultados}

\subsection{Caracterização dos restaurantes investigados}

Conforme delimitação metodológica, para consecução da pesquisa, ao todo, foram selecionados dez restaurantes, cujas particularidades serão destacadas. Considerando o tempo de atuação dos empreendimentos, observa-se uma permanência média de 18,2 anos no mercado. Esse período representa um valor considerável, tendo em vista o elevado índice de mortalidade das empresas brasileiras, o qual aponta para o desaparecimento de $60,2 \%$ das organizações após cinco anos de atuação (IBGE, 2019). Dos restaurantes investigados, o Rest. 8 é o que denota o maior tempo de atuação, com 46 anos, enquanto os Rest. 5, 6 e 7 aparecem como as empresas com o menor tempo de mercado, com cinco anos. Em relação ao tempo de atuação dos gestores entrevistados, também observou-se uma média relativamente elevada, correspondendo a 11,5 anos. Dentre os restaurantes investigados, destaca-se o Rest. 9, cujo gestor está há 34 anos atuando na organização, iniciando suas atividades concomitantemente ao período de fundação. Com menor tempo de atuação, é evidenciado o gestor do Rest. 6, apresentando seis meses em frente às 
atividades. Na Figura a seguir, estes dados são disponibilizados.

Sobre a quantidade de pessoas que frequentam os restaurantes, observa-se um valor médio de 142 comensais/dia. Juntos, os empreendimentos atendem cerca de 1420 clientes ao dia. O Rest. 2 é o que apresenta um maior fluxo de pessoas, com 350 comensais/dias, enquanto o Rest. 6 denota o menor valor, com 30 comensais/dia, seguido pelos Rest. 3, 7, 8 e 9, com fluxo médio de 60 comensais/ dia (Figura 2).

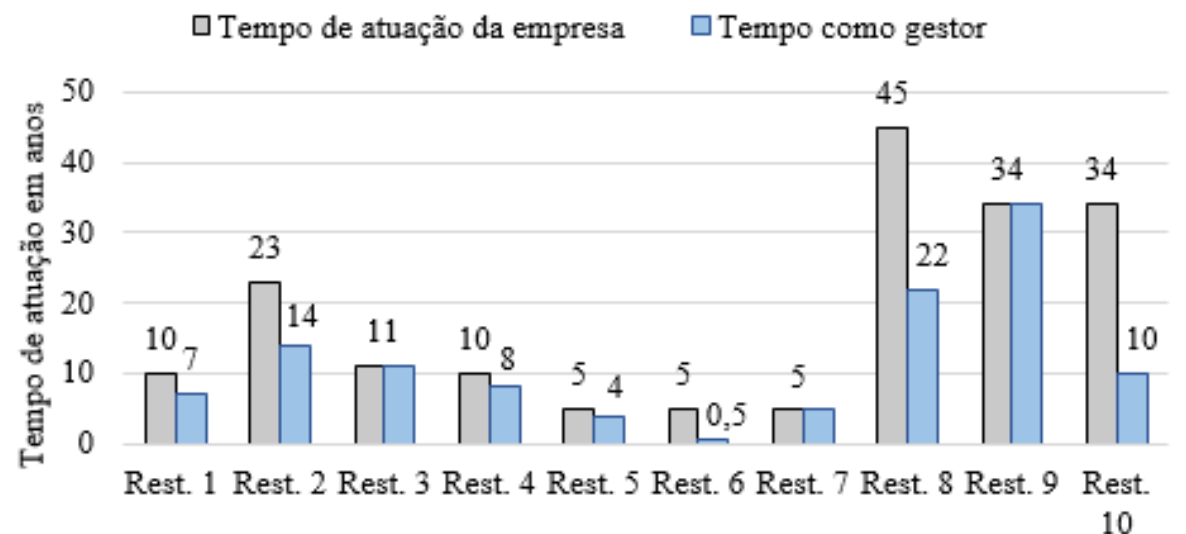

FIGURA 1 - Tempo de atuação dos restaurantes e gestores investigados.

FONTE: Elaboração própria.

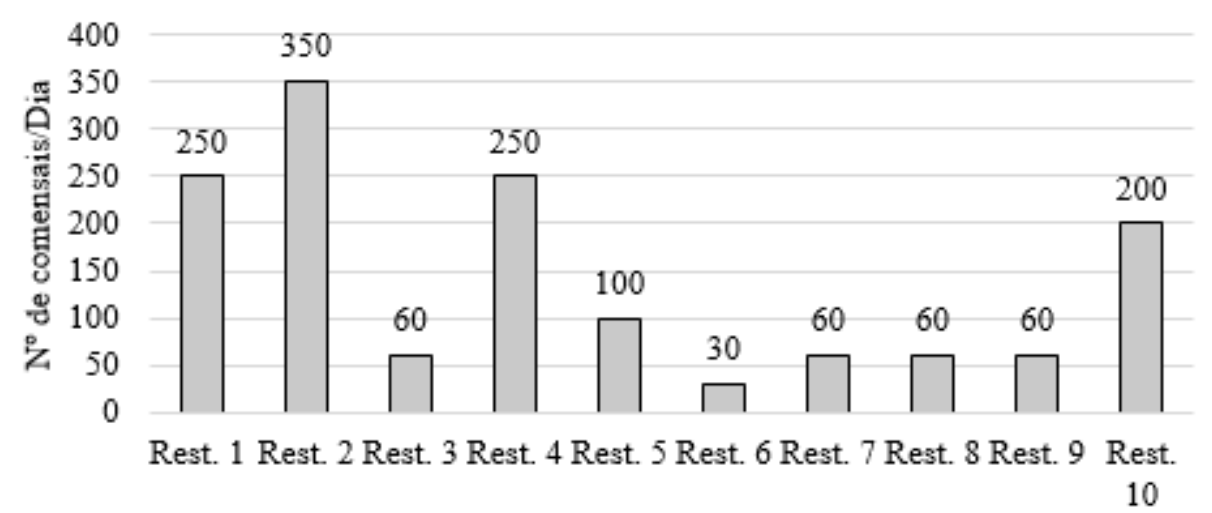

FIGURA 2 - Número de comensais/dia dos restaurantes investigados.

FONTE: Elaboração própria. 
Dentre as refeições servidas, observou-se que a maioria dos restaurantes $(80 \%)$ oferece somente o almoço, e apenas os Rest. 2 e 8 servem almoço e jantar. Considerando as modalidades, os resultados são semelhantes, sendo que $80 \%$ oferecem buffet e à la carte e $20 \%$ (Rest. 1 e 9) concentram-se somente no atendimento via buffet.

Dado o número de funcionários, os restaurantes possuem em média 14 colaboradores, destacando-se o Rest. 10 com 48 empregados. Os Rest. 6 e 9 são os que apresentam o menor número de funcionários, com três cada um. Considerando a classificação do Serviço Brasileiro de Apoio às Micro e Pequenas Empresas (SEBRAE, 2017) em relação ao porte das empresas segundo o número de empregados para o setor de comércio e serviços, os Rest. 1, 2 e 10 se enquadram como pequenas empresas (de 10 a 49 empregados), enquanto os demais como microempresas (até 9 empregados).

Por fim, sobre a modalidade de gestão dos restaurantes investigados, observou-se que 50\% dos restaurantes (Rest. 1, 3, 8, 9 e 10) desenvolvem uma gestão familiar que se caracteriza pela sucessão do poder decisório de maneira hereditária a partir de uma ou mais famílias, apresentando uma forte interação entre os membros e dificuldades na distinção entre as políticas e valores empresariais e familiares (Oliveira, 2006). É, portanto, diferente da gestão profissional, desempenhada neste caso pelos Rest. 2, 4, 5, 6 e 7 .

\subsection{Tipologia e classificação dos resíduos sólidos gerados}

Considerando os dados obtidos, por meio das entrevistas, observações e questionários, observa-se que as tipologias de resíduos sólidos não se diferem entre os restaurantes. Conforme a classificação quanto à origem, estabelecida pela PNRS, os resíduos gerados pelos estabelecimentos investigados enquadram-se no Art. 13 da Lei 12305/2010 como "Resíduos de estabelecimentos comerciais e prestadores de serviços" (Brasil, 2010).

$\mathrm{Na}$ fala dos entrevistados verifica-se certa consciência da diversidade de resíduos sólidos produzidos, com destaque para a menção de resíduos orgânicos, plástico e papel. Além disso, o óleo de cozinha, vidro, alumínio, isopor, lâmpadas e rejeitos também aparecem nos discursos. Utilizando-se da classificação dos resíduos conforme conteúdo, adaptado de Hoornweg \& Bhada-Tata (2012), e compilando os dados obtidos pelos instrumentos de coleta de dados, identificam-se as seguintes tipologias de resíduos gerados e seus respectivos exemplos, conforme discriminado na Tabela 2 .

Dentre os resíduos identificados, considerando a classificação de resíduos pela ABNT 10004:2004, que classifica os resíduos como Classe I - Perigosos e Classe II - Não perigosos (ABNT, 2004), observa-se que dois deles se enquadram como resíduos da classe I perigosos: o óleo de cozinha e as lâmpadas. Se não for descartado adequadamente, o óleo de cozinha pode representar grandes riscos ambientais, podendo contaminar o solo, a água e a atmosfera pela emissão de GEE (Gude \& Grant, 2013). Em relação às lâmpadas, a presença de mercúrio em sua composição torna-as um produto extremamente contaminante e, apesar de menos poluentes, as lâmpadas de LED ainda possuem potencial concentração de lixiviação de metais pesados, o que demanda atenção quanto ao seu descarte (Choi et al., 2019).

Além disso, um dos resíduos identificados, apesar de não perigoso e inerte (Classe II B), tam- 
TABELA 2 - Tipologia dos resíduos sólidos gerados nos restaurantes conforme conteúdo.

\begin{tabular}{cl}
\hline Tipologia de resíduos & \multicolumn{1}{c}{ Exemplos identificados } \\
\hline Orgânico & Sobras de alimentos (da preparação, buffet e clientes), óleo de cozinha. \\
\hline Papel/papelão & Caixas de papelão, sachês de açúcar e demais embalagens de produtos. \\
\hline Plástico & $\begin{array}{l}\text { Garrafas PET, embalagens de produtos de limpeza, embalagem de produtos para uso da cozinha, embala- } \\
\text { gem que reveste os talheres, canudos, colheres, sachês de temperos, copos descartáveis, isopor. }\end{array}$ \\
\hline Vidro & Garrafas, vidros quebrados, lâmpadas. \\
\hline Metal & Latas de alumínio, embalagem de produtos utilizados na cozinha, papel alumínio. \\
\hline Outros & Madeira: palitos de dente e caixas; rejeitos: guardanapos, resíduos dos banheiros.
\end{tabular}

FONTE: Elaboração própria.

bém deve ser destacado: o isopor. Ele é um tipo de plástico composto por cerca de $2 \%$ de poliestireno e $98 \%$ de ar e tem como característica a não decomposição (Associação Brasileira de Poliestireno Expandido [ABRAPEX], 2019). Apesar de reciclável, o processo de reciclagem do isopor ainda é caro e, devido ao desconhecimento e/ou falta de alternativas ao descarte, acabam sendo encaminhados junto ao lixo comum.

Esses resultados confirmam a grande variedade de resíduos sólidos que são gerados pelos restaurantes (Abdel-Shafy \& Mansour, 2018; Landry et al., 2018) e, dada essa diversidade, vê-se, portanto, como necessário o correto gerenciamento e descarte dos resíduos sólidos, a fim de reduzir os impactos e proporcionar maiores benefícios nos âmbitos ambiental, social e econômico (Okwesili et al., 2016).

\subsection{Gerenciamento e destinação final dos resíduos sólidos gerados nos restaurantes}

Apesar de extremamente importante em um contexto de grande geração e diversidade de resíduos sólidos, o gerenciamento demonstrou-se deficiente em todos os casos analisados, considerando a existências de pelo menos uma inconformidade relacionada à não geração, segregação, acondicionamento, coleta, tratamento e a disposição final dos resíduos sólidos.

Considerando as estratégias para evitar ou minimizar a geração de resíduos sólidos, os treinamentos são apontados por grande parte das organizações, no entanto, devido à falta de periodicidade em sua realização, resultados podem ser comprometidos. Além disso, tendo em vista a falta de tempo, capacitações informais no dia a dia tendem a ser ineficazes. Desta forma, seis práticas são tidas como realmente efetivas para esse propósito, sendo: treinamentos formais e periódicos, a produção conforme a demanda, a racionalização na disponibilização de materiais descartáveis, incentivos monetários aos funcionários, cartazes orientativos e o controle da quantidade de resíduos sólidos gerados, este último, inclusive, permite um acompanhamento e ação direcionada considerando a situação evidenciada.

Observa-se ainda, ao contrário do almejado, a existência de práticas que estimulam uma maior produção de resíduos sólidos, como fornecimento de materiais descartáveis e de pratos em tamanhos avantajados aos consumidores. Desta forma, é possível a busca por uma maior redução na geração, por 
meio da implantação de algumas iniciativas como: não disponibilização de canudos, copos e colheres de sobremesa descartáveis; redução do tamanho dos pratos, para evitar a indução ao consumidor de retirar uma quantidade maior que a necessária; e práticas educativas, como cartazes, para reduzir, por exemplo, o uso de guardanapos pelos consumidores, problema também em destaque nas entrevistas.

Apesar dos restaurantes indicarem realizar a separação e reciclagem dos resíduos, sendo a grande maioria nas tipologias orgânico e reciclável, observa-se incongruências entre teoria e prática, visto que foram visualizadas misturas de resíduos durante as observações in loco (Rest. 1, 3, 6, 7, 8, 9 e 10) (Figura 3). Segundo Hoornweg \& Bhada-Tata (2012), a prática da reciclagem de forma inadequada aumenta os resíduos encaminhados a aterros, bem como consiste em dispêndios financeiros, ao não permitir o retorno de materiais à economia.

Como forma de gerenciamento e tratamento de resíduos sólidos, os restaurantes destacam a utilização de sobras orgânicas para alimentação animal (Rest. 1, 3, 4, 5, 6, 7, 9 e 10). No entanto, essa prática é considerada inadequada pela Agência
Nacional de Vigilância Sanitária (ANVISA), devido à preocupação com a segurança da saúde animal pelos riscos de transmissão de doenças (Coelho et al., 2016). Além disso, o Ministério da Agricultura Pecuária e Abastecimento (MAPA) determina no Art. 14 da Instrução Normativa $n^{\circ} 44$ de 2017 a proibição da utilização de resíduos alimentares na alimentação de suínos como forma de erradicação e prevenção à febre aftosa (MAPA, 2007). Especificadamente, o Rest. 3 indica, além da utilização de resíduos orgânicos para a alimentação animal, a doação de sobras de alimentos do buffet à moradores de rua. Da mesma forma, a ANVISA, a partir da Resolução $n^{0}$ 216/2004, estabelece restrições para doação de sobras alimentares a pessoas, prevendo punições ao doador, caso o alimento resulte em alguma forma de intoxicação alimentar de quem o recebeu (ANVISA, 2004). No entanto, essa prática passa a ser regulamentada com a instituição da Lei $n^{\circ} 14.016$ de junho de 2020, a qual autoriza a doação de excedentes não comercializados ainda próprios para o consumo que estejam dentro do prazo de validade, não estejam comprometidos em sua

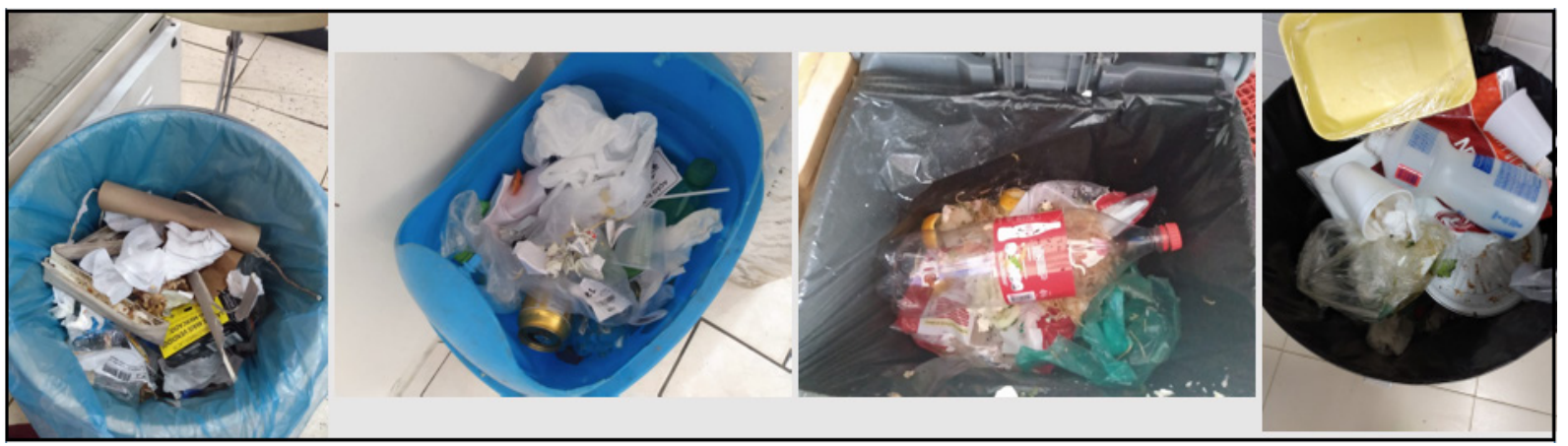

FIGURA 3 - Mistura de resíduos evidenciada nos restaurantes investigados.

FONTE: Elaboração própria. 
integridade e segurança sanitária e tenham mantidas suas propriedades nutricionais (Brasil, 2020).

Apenas o Rest. 2 realiza a compostagem a partir de resíduos orgânicos, método compreendido como positivo por reduzir o volume dos espaços ocupados em aterros e gerar benefícios no solo onde o composto orgânico, resultante da compostagem, é aplicado (Lima et al., 2017).

O controle gravimétrico não é efetuado pelos restaurantes investigados, da mesma forma que inexiste a mensuração dos custos decorrentes do descarte de resíduos sólidos, com exceção, para o primeiro caso, apenas dos Rest. 5 e 6, que realizam a quantificação dos resíduos orgânicos produzidos. Em relação à quantificação financeira das perdas, apenas o Rest. 5 possui um controle mais apurado. Esta seria uma prática importante, a fim de aumentar a consciência na geração de resíduos, bem como motivar uma melhor gestão, dado a tradução dos descartes para valores monetários que podem ser incorporados aos rendimentos econômicos do negócio (Corrêa \& Lange, 2011).

Também foi evidenciado pouco aproveitamento das sobras alimentares, o que seria capaz de reduzir o desperdício dos resíduos orgânicos. Segundo Hoornweg \& Bhada-Tata (2012), a reutilização ou, neste caso, o aproveitamento de resíduos tem o intuito de minimizar a geração destes ao modificar padrões de produção e consumo. Efetivamente, apenas os Rest. 4, 5, 8 e 10 demonstraram, a partir dos relatos, uma maior preocupação para com a questão.

A ausência do PGRS em todos os casos também corresponde a um dos problemas críticos de gerenciamento, ao consistir em um documento que orienta as ações da organização em relação a sua atuação e responsabilidade para com os resíduos sólidos por ela gerados (Voss et al., 2013), além de ser uma obrigatoriedade estipulada no Art. 20 da Lei $\mathrm{n}^{\circ}$ 12.305/2010 (Brasil, 2010).

Ademais, são evidenciadas inconformidades em relação às lixeiras e aos sacos plásticos utilizados, ambos com problemas de identificação e aos locais disponíveis para o acondicionamento de resíduos, devido à alocação de resíduos em corredores ou diretamente em via pública. Ainda foi identificada falta de limpeza nos locais de acondicionamento, bem como uma alocação de resíduos excessiva no espaço disponível.

Quanto à destinação final, apesar de grande parte dos resíduos recicláveis serem destinados à reciclagem, parcelas de resíduos orgânicos e os rejeitos são de responsabilidade municipal e, desta forma, não possuem a destinação correta, pois são encaminhados diretamente ao aterro controlado (Instituto Ambiental do Paraná [IAP], 2017). Quanto à questão, apenas aterros sanitários configuram-se como alternativa adequada, visto que possuem medidas para evitar os riscos dos descartes com a impermeabilização do solo (Ibrahim \& Mohamed, 2016).

Por fim, a prática da logística reversa também se demonstra restrita no gerenciamento de resíduos efetuado pelos restaurantes. Poucas empresas conhecem e/ou destinam certos resíduos, como lâmpadas, por meio da logística reversa, o que faz com que muitas vezes esses materiais sejam acondicionados ou destinados de forma incorreta. Essa situação corresponde aos resultados do estudo de Voss et al. (2013), em que práticas de logística reversa foram encontradas de formas precárias ou ausentes nas organizações investigadas.

A fim de obter um panorama geral das condições de gestão de resíduos sólidos nas organizações investigadas, foram listadas 12 práticas tidas como 
esperadas nas fases de gerenciamento, conforme discussão apresentada neste tópico. Com base nos resultados, os restaurantes foram classificados como conformes, atribuindo-se o valor de 1 (um), ou não conformes, cujo valor correspondente é 0 (zero), para cada uma dessas práticas. Considerando a não autorização da observação interna, para o Rest. 2, em alguns pontos foi aplicada a condição NA (não se aplica), devido à impossibilidade de conclusões efetivas sobre a prática avaliada. Ao final, a partir do somatório das pontuações, foi possível obter um score para análise, conforme apresentado na Tabela 3.

Com base nas práticas avaliadas, observa-se que, dentre os restaurantes investigados, o Rest. 5 é o que apresenta uma melhor gestão. A empresa denota preocupação com a questão dos resíduos sólidos, adotando o processo de reciclagem, a logística reversa e o aproveitamento de sobras. Além disso, dispõe de práticas para reduzir a geração, como capacitações formais, produção conforme demanda, incentivos financeiros aos funcionários e cartazes orientativos.

O Rest. 5 está atuando há cinco anos no mercado, cuja gestão atual se mantém por quatro anos. Em média, são atendidos 100 consumidores ao dia, com opções nas modalidades de buffet e à la carte. Esse melhor desempenho pode ser justificado dado uma gestão profissional que se preocupa com o controle sobre a quantidade e o valor decorrente dos descartes dos resíduos orgânicos produzidos no estabelecimento. Essas práticas, consequentemente, possibilitam uma reflexão dos resíduos como recursos valiosos (Jeswani \& Azapagic, 2016).

Os piores resultados são evidenciados nos Rest. 3, 8 e 9. Considerando o Rest. 3, observa-se apenas a doação de sobras alimentares do buffet a moradores de rua, prática em consonância com a lei $\mathrm{n}^{\mathrm{o}}$ 14.016/2020 (Brasil, 2020). No Rest. 8 destaca-se somente a preocupação com o aproveitamento de sobras, e o Rest. 9 busca apenas reduzir o volume gerado por meio da produção sob demanda. Cabe destacar que os Rest. 3, 8 e 9, que apresentaram resultados deficientes em relação ao gerenciamento de resíduos sólidos, consistem em empresas de menor porte, com gestão familiar e tempo relativamente elevado de atuação no mercado, bem como dos gestores que estão à frente das atividades, o que pode denotar certos aspectos culturais e hábitos que são traduzidos em ações ao longo dos anos (Durgekar, 2016; Thyberg \& Tonjes, 2016; Chen, 2019).

Esses resultados não satisfatórios em relação à gestão dos resíduos podem emergir diante das dificuldades relatadas, tais como falta de tempo, cultura da população, distração e rotatividade dos funcionários. Além disso, o desconhecimento das legislações, por parte dos gestores e funcionários, a falta de incentivo governamental, bem como a ausência de cobranças por parte do poder público e órgãos reguladores, evidenciados nos instrumentos de pesquisa, pode justificar a não preocupação dos restaurantes em gerir adequadamente seus resíduos.

\subsection{Relação das práticas identificadas com as regulamentações e legislações vigentes}

A fim de compreender as atuais condições de gerenciamento dos resíduos sólidos nos restaurantes considerando aspectos legais, este tópico concentra-se em comparar os resultados obtidos, com as regulamentações e legislações vigentes, especialmente considerando o contido na PNRS e em leis estaduais e municipais diretamente relacionadas. 
TABELA 3 - Conformidades e não conformidades em relação ao gerenciamento de resíduos sólidos dos restaurantes investigados. Legenda: 0 = Não conforme; 1 = Conforme; NA = Não se aplica.

\begin{tabular}{|c|c|c|c|c|c|c|c|c|c|c|}
\hline Práticas efetuadas & Rest.1 & Rest.2 & Rest.3 & Rest.4 & Rest.5 & Rest.6 & Rest.7 & Rest.8 & Rest.9 & Rest.10 \\
\hline $\begin{array}{l}\text { 1. Existem medidas efetivas para a não geração e redução de resí- } \\
\text { duos sólidos }\end{array}$ & 1 & 1 & 0 & 1 & 1 & 1 & 1 & 0 & 1 & 1 \\
\hline $\begin{array}{l}\text { 2. Realiza procedimentos de reciclagem/separação de resíduos de } \\
\text { forma adequada }\end{array}$ & 0 & NA & 0 & 1 & 1 & 0 & 0 & 0 & 0 & 0 \\
\hline $\begin{array}{l}\text { 3. Realiza algum tipo de gerenciamento/tratamento de resíduos só- } \\
\text { lidos }\end{array}$ & 0 & 1 & 1 & 0 & 0 & 0 & 0 & 0 & 0 & 0 \\
\hline $\begin{array}{l}\text { 4. Possui alguma forma de controle gravimétrico da geração de re- } \\
\text { síduos }\end{array}$ & 0 & 0 & 0 & 0 & 1 & 1 & 0 & 0 & 0 & 0 \\
\hline $\begin{array}{l}\text { 5. Tem controle sobre perdas financeiras decorrentes do desperdício } \\
\text { de alimentos }\end{array}$ & 0 & 0 & 0 & 0 & 1 & 0 & 0 & 0 & 0 & 0 \\
\hline $\begin{array}{l}\text { 6. Busca efetivamente realizar o aproveitamento de sobras alimen- } \\
\text { tares }\end{array}$ & 0 & 0 & 0 & 1 & 1 & 0 & 0 & 1 & 0 & 1 \\
\hline 7. Possui o PGRS & 0 & 0 & 0 & 0 & 0 & 0 & 0 & 0 & 0 & 0 \\
\hline $\begin{array}{l}\text { 8. Existem lixeiras específicas, adequadas e identificadas para o ar- } \\
\text { mazenamento de resíduos sólidos }\end{array}$ & 0 & NA & 0 & 0 & 1 & 1 & 0 & 0 & 0 & 1 \\
\hline $\begin{array}{l}\text { 9. São utilizados sacos plásticos identificados para acondicionar os } \\
\text { resíduos }\end{array}$ & 0 & 0 & 0 & 0 & 0 & 0 & 0 & 0 & 0 & 1 \\
\hline $\begin{array}{l}\text { 10. Os resíduos são acondicionados em locais adequados e de modo } \\
\text { adequado até a posterior coleta }\end{array}$ & 1 & 1 & 0 & 1 & 0 & 0 & 0 & 0 & 0 & 0 \\
\hline 11. Todos os resíduos gerados são destinados de forma correta & 0 & 0 & 0 & 0 & 0 & 0 & 0 & 0 & 0 & 0 \\
\hline 12. O restaurante conhece e aplica a logística reversa efetivamente & 0 & 0 & 0 & 1 & 1 & 1 & 1 & 0 & 0 & 0 \\
\hline TOTAL & 2 & 3 & 1 & 5 & 7 & 4 & 2 & 1 & 1 & 4 \\
\hline
\end{tabular}

FONTE: Elaboração própria. 
Conforme dispõe o Art. 20 da Lei n. $12.305 / 2010$, estabelecimentos comerciais que geram resíduos perigosos, ou que, por sua natureza, composição ou volume, não sejam equiparados aos resíduos domiciliares, estão sujeitos à elaboração do PGRS (Brasil, 2010). Os restaurantes investigados, por produzirem uma quantidade superior a 120 litros de resíduos sólidos ao dia, enquadram-se como grandes geradores (IBAM, 2001), além disso, são responsáveis pela geração de dois resíduos perigosos: óleo de cozinha e lâmpadas, estando, assim, sujeitos às determinações do Art. 20 da PNRS (Brasil, 2010). No entanto, nenhum deles atende ao preceito da necessidade de existência do PGRS. Sobre essa questão, apesar dos Rest. 5, 7 e 10 afirmarem possuir um documento orientativo sobre o correto gerenciamento, este não atende aos requisitos mínimos exigidos do plano.

A não elaboração do PGRS pelos restaurantes pode ser justificada pela falta de informações e cobranças do poder público comprovada pelo desconhecimento da existência da lei pela maior parte dos entrevistados, o que caracteriza uma implementação malsucedida das regulamentações instituídos sobre resíduos sólidos até então (Potdar et al., 2016). Especialmente, considerando a realidade municipal, a inexistência do PMGIRS, de certa forma, não oferece estímulos ao cumprimento da lei pelos demais atores, apesar deste fato não eliminar a responsabilidade dos restaurantes pela elaboração, implementação e operacionalização do PGRS (Brasil, 2010).

Em relação à responsabilidade pela gestão dos resíduos sólidos, tanto a lei estadual quanto municipal incumbem os próprios geradores dessa tarefa. Conforme Art. $4^{\circ}$ da Lei n. 12.493/1999, as atividades geradoras de resíduos, de qualquer natu- reza, são responsáveis pelo seu acondicionamento, armazenamento, coleta, transporte, tratamento, disposição final e pelos passivos ambientais por elas ocasionados (Paraná, 1999). O código de posturas municipal, contido na Lei n. 4.229/2016, por sua vez, denota a responsabilidade municipal pela gestão dos resíduos domiciliares, não abrangendo, neste caso, os resíduos provenientes das atividades comerciais (Irati, 2016). No entanto, o que se observa é ainda uma elevada dependência dos restaurantes pesquisados pelos serviços de coleta seletiva prestados pela prefeitura, cuja taxa corresponde ao mesmo valor fixo cobrado para a coleta domiciliar. Isso, de certo modo, onera os cofres públicos e beneficia os estabelecimentos ao tornar facilitado o destino final dos resíduos por eles produzidos, independentemente da quantidade gerada.

A PNRS, dentro da temática de gestão dos resíduos, aborda ainda a logística reversa como um de seus instrumentos (Brasil, 2010). Dada as características da atividade da alimentação fora do lar, os restaurantes destacam-se como consumidores de produtos que devem fazer parte da logística reversa, especialmente óleo de cozinha e lâmpadas. No entanto, observa-se, nos casos investigados, desconhecimento por parte das empresas quanto ao assunto, bem como práticas inadequadas de gestão, considerando, especificamente, o segundo item. Dos Restaurantes abrangidos na pesquisa, apenas os Rest. 4, 5, 6 e 7 informaram realizar a destinação correta das lâmpadas pautada na logística reversa. Ademais, os Rest. 2 e 10 possuem dúvidas sobre o que é feito com o material; os Rest. 1 e 3 costumam estocá-lo sem dar um destino; enquanto dois deles (Rest. 8 e 9) acabam descartando junto ao lixo comum. 
Essa situação evidenciada pode ser provocada pela falta de informações sobre as práticas de logística reversa no município e de regulamentações mais rígidas que imponham medidas de controle para comerciantes e consumidores. Além disso, a ausência de tecnologia e infraestrutura e questões econômicas no que concerne aos investimentos necessários também podem constituir barreiras ao desenvolvimento desta prática no município.

Por fim, apesar de não se referir a uma regulamentação formal, é pertinente abordar nessa discussão o acordo municipal com os estabelecimentos comerciais, informado pela Secretaria do Meio Ambiente e Ecologia. Nesse acordo, o município, buscando possibilitar uma contrapartida social, solicita no momento de renovação do alvará a assinatura por parte das empresas de um termo que determina o encaminhamento do material reciclável, por meio da coleta seletiva, para a cooperativa e associação de catadores. Observa-se, porém, que a existência desse acordo não foi citada por nenhum dos restaurantes investigados. Além disso, quase todos os estabelecimentos realizam a venda de pelo menos um tipo de reciclável, com exceção apenas dos Rest. 6, 8 e 9. Isso denota, novamente, a ineficiência das normas/regulamentações relacionadas aos RSU, bem como a baixa interação entre o poder público e as empresas que operam no município.

\subsection{O gerenciamento de resíduos sólidos e a sustentabilidade}

A gestão dos resíduos sólidos constitui uma questão complexa de sustentabilidade, visto que deve ser viável financeiramente, socialmente justa e ambientalmente correta (Abdel-Shafy \& Mansour,
2018). Partindo-se deste princípio, este tópico elucida a relação entre as práticas de gerenciamento de resíduos sólidos adotadas nos restaurantes investigados e a sustentabilidade, destacando pontos positivos e negativos evidenciados nos três pilares que compõem o conceito: ambiental, social e econômico.

Em relação à dimensão ambiental, pontos positivos obtêm destaque nas práticas de eliminação ou redução na geração de resíduos sólidos, tais como treinamentos formais e periódicos, recompensas financeiras relacionadas às boas práticas, cartazes orientativos, produção conforme a demanda, racionalização no uso e entrega de materiais descartáveis aos clientes e controle de quebras produtivas, devido à capacidade de evitar o envio de maiores quantidades de resíduos a locais inadequados de descarte (Pistorello et al., 2015). Além disso, a reciclagem de resíduos, a compostagem, a destinação correta do óleo de cozinha e a prática da logística reversa efetuada por alguns restaurantes destacam-se como ações contributivas à preservação e redução da poluição provocada ao meio ambiente.

Dentre os aspectos negativos, denota-se o descarte do isopor junto ao lixo comum, a não realização do controle gravimétrico de resíduos pela maioria dos restaurantes, o que impede um acompanhamento e busca de soluções aos gargalos existentes, e a falta de locais adequados para o acondicionamento de resíduos em alguns casos. Além disso, a ausência de identificação das lixeiras, nos sacos plásticos e recipientes de coleta de óleo de cozinha usado, dificulta a correta segregação resultando no problema de mistura de resíduos, e também é evidenciada como um dos pontos negativos. Por fim, destacam-se como demais práticas prejudiciais ao aspecto ambiental, o elevado uso 
de materiais descartáveis disponibilizados por alguns restaurantes, o descarte de lâmpadas junto ao lixo comum ou estoque em locais inadequados e a destinação de rejeitos e resíduos orgânicos em aterro controlado.

Grande parte desses resultados podem ser equiparados aos obtidos na pesquisa de Peruchin et al. (2013) que, ao investigar um restaurante escola, identificou práticas inadequadas de gestão, tais como o descarte de lâmpadas no lixo comum, $\mathrm{o}$ acondicionamento de resíduos em sacos plásticos sem identificação, a falta de lixeiras específicas e identificadas e os consequentes problemas na separação de resíduos sólidos.

No que concerne ao pilar social, salientam-se como pontos positivos a preocupação com a segurança dos funcionários, por um dos restaurantes; a armazenagem do vidro em caixas com identificação; a coleta de materiais recicláveis por catadores independentes; a doação de sobras de alimentos adequados ao consumo para moradores de rua e a separação de resíduos e louças dos clientes com o objetivo de evitar contaminação. Entre os aspectos negativos, observa-se a inexistência de projetos visando benefícios comunitários; a dependência da coleta seletiva que demanda maiores investimentos públicos; o não cumprimento do acordo com a prefeitura de fornecimento de materiais recicláveis para associação e cooperativa; a falta de limpeza adequada em determinados locais de acondicionamento de resíduos com condições não favoráveis ao trabalho; e o baixo envolvimento com o aproveitamento de sobras e demais resíduos orgânicos, cujos impactos sociais prevalecem dadas as questões da segurança alimentar (Chen, 2019).

No que concerne ao pilar econômico da sustentabilidade, embora descumpram o acordo firmado com a prefeitura, como ponto positivo, alguns restaurantes obtêm retornos financeiros com a venda dos materiais recicláveis, no entanto, nenhum deles tem estimado o valor exato obtido a partir dessa prática. Por outro lado, o baixo índice de aproveitamento das sobras alimentares e resíduos de preparação correspondem a dispêndios financeiros, assim como a falta de controle e estimativa de perdas em reais decorrentes do descarte de resíduos não permite reflexões e esforços direcionados a minimizar a geração visando ganhos monetários. Dentre os restaurantes investigados, apenas o Rest. 5 mantém um controle mais apurado em relação aos resíduos orgânicos, estimando a perda de cerca de $\mathrm{R} \$ 17.780,00$ ao ano, decorrente do desperdício de alimentos. Oportuniza a partir desde dado refletir sobre os impactos econômicos decorrentes da implementação de um plano de gestão de resíduos sólidos nos estabelecimentos. Todos esses pontos positivos e negativos elencados sob a perspectiva dos pilares da sustentabilidade estão compilados na Tabela 4.

De um modo geral, as empresas investigadas não visualizam a sustentabilidade como oportunidade de negócios. Práticas são vistas ainda como caras pelo Rest. 1, da mesma forma que acredita que os clientes buscam apenas por uma boa comida, higiene e atendimento. Esse segundo ponto é também corroborado pelo Rest. 10 ao tratar sobre a questão. Essa concepção corresponde ao descrito por Nidomulo et al. (2009), os quais apontam que muitas organizações não conseguem compreender a sustentabilidade como algo positivo ao negócio, tendendo a vê-la como um custo adicional ou algo desconectado dos objetivos estratégicos. 
TABELA 4 - Aspectos positivos e negativos do gerenciamento de resíduos sólidos efetuados nos restaurantes em relação à sustentabilidade.

\begin{tabular}{ll}
\hline & \multicolumn{1}{c}{ Aspectos positivos } \\
\hline - & Treinamentos formais e periódicos dos funcionários \\
& sobre resíduos sólidos (Rest. 1, 4, 5, 6, 7 e 10); \\
- & Recompensas monetárias relacionadas a boas \\
& práticas em relação aos resíduos sólidos (Rest. 5). \\
- & Cartaz orientativo sobre resíduos sólidos no local de \\
& acondicionamento (Rest. 5); \\
- & Cartazes com orientações sobre segregação de \\
& resíduos sólidos e a higienização dos recipientes \\
& (Rest. 10). \\
- & Reutilização de sacos plásticos nos banheiros e não \\
& fornecimento de canudos sem prévia solicitação \\
& (Rest. 1); \\
- & Reciclagem de resíduos (quando efetuada de \\
& maneira correta) (Rest. 4 e 5); \\
Ambiental & Produção conforme estimativa da demanda (Rest. 2, \\
& $4,6,7,9$ e 10); \\
- & Controle da quantidade de quebras da produção \\
& (Rest. 5 e 6); \\
- & Compostagem (Rest. 2); \\
- & Destinação correta do óleo de cozinha usado (todos \\
& os Rest.); \\
- & Logística reversa (Rest. 4, 5, 6 e 7) \\
&
\end{tabular}

- Inexistência de projetos relacionados, por exemplo, à prática da compostagem que poderia

- Preocupação com a segurança dos funcionários (Rest. 1);

- Descarte do isopor junto ao lixo comum;

- Não realização do controle gravimétrico dos resíduos gerados e encaminhados à destinação final (Exceção Rest. 5 e 6 para resíduos orgânicos);

- Falta de locais apropriados para acondicionamento de resíduos (Rest. 3, 6, 8, 9 e 10);

- Falta de identificação das lixeiras (Rest. 1, 3, 4, 7, 8 e 9);

- Falta de identificação nos sacos plásticos (Exceção Rest. 10);

- Mistura de resíduos (Rest. 1, 3, 6, 7, 8, 9 e 10);

- Elevado uso de materiais descartáveis, como colheres e copos (Rest. 2);

- Descarte de lâmpadas junto ao lixo comum (Rest. 8 e 9) ou estoque em locais inapropriados (Rest. $3)$;

- Destinação incorreta dos rejeitos e resíduos orgânicos encaminhados pela prefeitura (aterro controlado) (Todos os Rest.).

- Armazenagem do vidro em caixas identificadas para evitar acidentes (Rest. 1 e 5);

Social

- Coleta de papelão, plástico e vidro por catadores independentes (Rest. 2);

- Doação de sobras alimentares em condições de consumo a moradores de rua (Rest. 3);

- Separação dos resíduos e louças dos clientes a fim de evitar contaminação (Exceção Rest. 4). beneficiar os próprios restaurantes e a comunidade (Todos os Rest.);

- Dependência da coleta seletiva, sendo os resíduos gerados equiparados a resíduos domiciliares (Todos os Rest.);

- Não cumprimento do acordo com a prefeitura de encaminhar materiais recicláveis para a coleta seletiva (Exceção Rest. 6, 8 e 9);

- Falta de limpeza do local de acondicionamento (Rest. 5) / acúmulo excessivo de resíduos (Rest. 7);

- Sobras de alimentos e resíduos de preparação que poderiam ser doados ou utilizados em novas receitas (Todos os Rest.).

- Baixo índice de aproveitamento das sobras alimentares e cascas de frutas e vegetais (Todos os Rest.);

Econômico

- Retornos financeiros com a venda de resíduos sólidos recicláveis (Rest. 1, 2, 3, 4, 5, 7 e 10).

- Falta de controle e estimativa das perdas em reais decorrentes do descarte de resíduos sólidos (Exceção Rest. 5 para resíduos orgânicos).

\footnotetext{
FONTE: Elaboração própria.
} 
Alguns restaurantes (Rest. 2 e 3) destacam a necessidade de maior consciência por parte dos consumidores a fim de que se torne vantajoso investir em sustentabilidade, bem como apontam para o individualismo das pessoas como uma das barreiras (Rest. 2 e 6). Além disso, os Rest. 3, 4, 7 , 8,9 e 10 dizem não sentir pressão ou necessidade de implementar tais práticas. Conforme apontam Claro et al. (2008), a adoção de práticas sustentáveis pelas empresas é em grande parte resultado das críticas e pressões existentes em seu ambiente de atuação e, na ausência destas, as organizações tendem a não mover esforços nessa direção. Além disso, a inexistência de fortes regulamentos e monitoramento de entes privados pressionadores e de um ambiente em que o comportamento sustentável esteja institucionalizado, dificulta a orientação estratégica para a sustentabilidade (Campbell, 2007). Dessa forma é necessária uma mudança que emerja de todos os atores que estão relacionados: organizações, indivíduos, consumidores e demais partes interessadas, a fim de que desempenhem um papel importante na busca da sustentabilidade.

\section{Considerações finais}

O presente estudo teve como objetivo principal investigar o gerenciamento e o descarte final de resíduos sólidos em restaurantes no município de Irati, PR, e sua relação com a sustentabilidade. A pesquisa foi desenvolvida por meio da realização de estudos de casos múltiplos em 10 restaurantes situados no município supracitado.

Foi possível verificar que os resíduos sólidos gerados não se diferem entre as organizações, cujas tipologias identificadas reafirmam a diversidade de resíduos gerados pelos restaurantes e a necessidade de um correto gerenciamento, especialmente dos resíduos perigosos. No entanto, de um modo geral, denotou-se uma gestão deficiente dos resíduos sólidos, considerando a existência de inconformidades relacionadas à não geração, segregação, acondicionamento, coleta, tratamento e a disposição final, bem como a ausência do PGRS.

Além disso, poucas ações vinculadas ao cumprimento de leis e regulamentos relacionados são observadas. Os restaurantes, apesar de serem classificados como grandes geradores, não possuem o PGRS e não se responsabilizam pela destinação de todos os resíduos sólidos por eles gerados, observando-se grande dependência dos serviços de coleta seletiva prestados pela prefeitura, cuja taxa é equiparada aos domicílios. Isso é também evidenciado na prática limitada da logística reversa, bem como no não cumprimento do acordo relatado pela prefeitura municipal, no que concerne ao encaminhamento do material reciclável para cooperativa e associação de catadores.

Considerando a relação entre o gerenciamento e práticas sustentáveis, foram destacados pontos positivos e negativos nos três pilares, porém, de um modo geral, as empresas investigadas não compreendem a sustentabilidade como uma oportunidade de negócios, tendo, portanto, dificuldade de associar a sustentabilidade aos objetivos estratégicos da organização.

Como dificuldades e possíveis justificativas a esses resultados, são apresentadas a falta de tempo, a cultura da população, distração e a rotatividade dos funcionários. Ademais, o desconhecimento de legislações e o pouco apoio ou cobrança por parte do poder público constituem um dos principais motivos para essas condições encontradas na realidade local. 
Dada a continuação das atuais condições evidenciadas, efeitos se traduzem em passivos ambientais que refletem na qualidade de vida de toda a coletividade. Desta forma, vê-se como necessário um maior enfoque das organizações à gestão dos resíduos sólidos, a partir de implantação de medidas adequadas, tais como: redução no uso e fornecimento de produtos/embalagens descartáveis; ênfase para a reciclagem correta e tratamentos eficientes de resíduos como a compostagem; adequação das áreas físicas de acondicionamento de resíduos, bem como das lixeiras e sacos plásticos, prezando por sua identificação; melhor aproveitamento das sobras alimentares; iniciativas de conscientização da comunidade em geral sobre o descarte de resíduos e de projetos que visem o bem-estar coletivo; maior controle sobre a quantidade gerada de resíduos e encaminhada à destinação final, bem como sobre o valor decorrente dos desperdícios; entre outras. Além disso, torna-se essencial o foco na elaboração do PGRS, por parte dos restaurantes, a fim de direcionar sua atuação, visando melhores resultados ambientais, sociais e econômicos.

Do ponto de vista da gestão pública, vê-se como fundamental a elaboração do PMGIRS do município, reforçando a questão de responsabilização dos empreendimentos pela destinação dos resíduos ou instituindo medidas que os diferenciem dos geradores de resíduos domiciliares, como a ampliação, por exemplo, da taxa cobrada. Parcerias público-privadas e instituição de políticas públicas direcionadas também são vistas como alternativa a um maior controle e melhor comunicação para fazer valer acordos, legislações e regulamentos em vigência, eliminando práticas inadequadas. Ainda, uma cooperação, incluindo demais instituições e a comunidade geral poderia resultar em soluções conjuntas para demais problemas evidenciados, sendo estas adaptadas a realidade local e às noções de sustentabilidade.

\section{Referências}

Abdel-Shafy, H. I.; Mansour, M. S. M. Solid waste issue: sources, composition, disposal, recycling, and valorization. Egyptian Journal of Petroleum, 27(4), 1275-1290, 2018. doi: 10.1016/j.ejpe.2018.07.003

ABIA - Associação Brasileira da Indústria de Alimentos. Números do setor, 2018. Disponível em: <https://www. abia.org.br/vsn/tmp_6.aspx?id=16>. Acesso em: jan. 2020.

ABNT - Associação Brasileira de Normas Técnicas. NBR 10004: Resíduos sólidos - classificação. Rio de Janeiro, 2004. Disponível em: $<$ https://analiticaqmcresiduos.paginas.ufsc.br/files/2014/07/Nbr-10004-2004-Classificacao-De-Residuos-Solidos.pdf $>$. Acesso em: jan. 2020.

ABRAPEX - Associação Brasileira de Poliestireno Expandido. Características e reciclagem, 2019. Disponível em: $<$ http://www.abrapex.com.br/02Caracter.html $>$. Acesso em: nov. 2019.

ABRASEL - Associação Brasileira de Bares e Restaurantes. Desperdicio de alimentos em restaurantes chega a seis mil toneladas no país, 2018. Disponível em: <https://abrasel. com.br/noticias/noticias/desperdicio-de-alimentos-em-restaurantes-chega-a-seis-mil-toneladas-no-pais/>. Acesso em: jan. 2020.

ABRELPE - Associação Brasileira de Empresas de Limpeza Pública e Resíduos Especiais. Panorama dos Resíduos Sólidos no Brasil 2020, 2020. Disponível em: <https://abrelpe. org.br/panorama-2020/>. Acesso em: abr. 2021.

Aleluia, J.; Ferrão, P. Characterization of urban waste management practices in developing Asian countries: a new analytical framework based on waste characteristics and urban dimension. Waste Management, 58, 415-429, 2016. doi: 10.1016/j.wasman.2016.05.008

Altenburg, T.; Pegels, A. Sustainability-oriented innovation systems: managing the green transformation. In- 
novation and Development, 2(1), 5-22, 2012. doi: 10.1080/2157930X.2012.664037

Alves, M. G.; Ueno, M. Identificação de fontes de geração de resíduos sólidos em uma unidade de alimentação e nutrição. Ambiente e Água, 10(4), 874-888, 2015. doi: 10.4136/ ambi-agua. 1640

Alves, R. R. Sustentabilidade empresarial e mercado verde. Petrópolis: Vozes, 2019.

ANVISA - Agência Nacional de Vigilância Sanitária. Resolução $n^{\circ} 216$, de 15 de setembro de 2004. Dispõe sobre Regulamento Técnico de Boas Práticas para Serviços de Alimentação. Brasília: DOU de 16/09/2004.

Bardin, L. Análise de conteúdo. São Paulo: Edições 70, 2011.

Boff, L. Sustentabilidade: o que é, o que não é. Petrópolis: Vozes, 2017.

Brasil. Lei n. 12.305, de 02 de agosto de 2010. Institui a Política Nacional de Resíduos Sólidos; altera a Lei n. 9.605, de 12 de fevereiro de 1998; e dá outras providências. Brasília: DOU de 03/08/2010.

Brasil. Lei n. 14.016 de 23 de junho de 2020. Dispõe sobre o combate ao desperdício de alimentos e a doação de excedentes para o consumo humano. Brasília: DOU de 24/06/2020.

Campbell, J. L. Why would corporations behave in socially responsible ways? An institutional theory of corporate social responsibility. Academy of Management Review, 32(3), 946967, 2007. doi: 10.5465/amr.2007.25275684

Carneiro, C. L. Gerenciamento integrado de resíduos sólidos e sua aplicabilidade em produção de refeições: um diálogo interdisciplinar. Holos, 1(30), 68-74, 2014. doi: 10.15628/ holos.2014.1527

Chen, H. S. Environmental concerns and food consumption: what drives consumers' actions to reduce food waste? Journal of International Food \& Agribusiness Marketing, 31(3), 1-20. 2019. doi: 10.1080/08974438.2018.1520179

Choi, Y.; Choi, H.; Rhee, S. Estimation on hazardous characteristics of the components from linear type of end-of-life light-emitting diode lamps. Journal of Material Cycles and Waste Management, (special edition), 1-8, 2019. doi:

\subsection{7/s10163-019-00913-6}

Claro, P. B. O.; Claro, D. P.; Amâncio, R. Entendendo o conceito de sustentabilidade nas organizações. Revista de Administração da Universidade de São Paulo, 43(4), 289-300, 2008. Disponível em: https://www.revistas.usp. br/rausp/article/view/44483

Coelho, D. C. J.; Gouvêa, C. A. K.; Hurtado, A. L. B.; Macedo, M. Resíduos alimentares: impactos, possíveis usos e legislação. Espacios, 37(16), 12-17, 2016. Disponível em: https://www.revistaespacios.com/a16v37n16/16371612. html

Corrêa, M. S.; Lange, L. C. Gestão dos resíduos sólidos no setor de refeição coletiva. Pretexto, 12(1), 29-54, 2011. doi: 10.21714/pretexto.v12i1.659

Creswell, J. W. Projeto de pesquisa: métodos qualitativo, quantitativo e misto. Porto Alegre: Artmed, 2010.

Dawson, C. Introduction to research methods: a practical guide for anyone undertaking a research project. United Kingdom: How to Books, 2009.

De Clercq; Wen, Z.; Fan, F.; Caicedo, L. Biomethane production potential from restaurant food waste in megacities and project level-bottlenecks: a case study in Beijing. Renewable and Sustainable Energy Reviews, 59(1), 1676-1685, 2016. doi: 10.1016/j.rser.2015.12.323

Durgekar, V. Towards sustainable waste management through technological innovations, effective policy, supply chain integration \& participation. Procedia Environmental Sciences, 35(1), 140-149, 2016. doi: 10.1016/j. proenv.2016.07.061

Elkington, J. Cannibals with forks: the triple bottom line of 21 st century business. United Kingdom: Capstone Publishing Limited, 1997.

FAO - Food and Agriculture Organization of the United Nations. The state of food security and nutrition in the world: safeguarding against economic slowdowns and downturns. 2019. Disponível em: <http://www.fao.org/3/ca5162en/ ca5162en.pdf>. Acesso em: dez. 2019.

Gude, V. G.; Grant, G. E. Biodiesel from waste cooking oils via direct sonication. Applied Energy, 109(1), 135-144, 2013. doi: 10.1016/j.apenergy.2013.04.002 
Hoornweg, D.; Bhada-Tata, P. What a waste: a global review of solid waste management. Urban development and local government unit. The World Bank, Washington, DC, 2012.

Hopwood, B.; Mellor, M.; O’brien, G. Sustainable development: mapping different approaches. Sustainable Development, 13(1), 38-52, 2005. doi: 10.1002/sd.244

IAP - Instituto Ambiental do Paraná. Relatório da situação da disposição final de resíduos sólidos urbanos no estado do Paraná 2017. Laudo Técnico n. 2, 2017. Disponível em: $<\mathrm{http}$ ://www.iap.pr.gov.br/arquivos/File/Diagnostico_Disposicao_Final_de_RSU_2017.pdf $>$.Acesso em: abr., 2021.

IBAM - Instituto Brasileiro de Administração Municipal. Manual de gerenciamento integrado de resíduos sólidos, 2001. Disponível em: <http://www.resol.com.br/cartilha4/ manual.pdf $>$ Acesso em: nov. 2019.

IBGE - Instituto Brasileiro de Geografia e Estatística. Demografia das empresas e estatísticas de empreendedorismo: 2017. Rio de Janeiro: IBGE, 2019. Disponível em: <https:// biblioteca.ibge.gov.br/visualizacao/livros/liv101671.pdf>. Acesso em: abr. 2021.

IBGE - Instituto Brasileiro de Geografia e Estatística. Estimativas da população, 2020. Disponível em: <https:// www.ibge.gov.br/estatisticas/sociais/populacao/9103-estimativas-de-populacao.html? $=\& \mathrm{t}=$ downloads $>$. Acesso em: abr. 2021

IBGE - Instituto Brasileiro de Geografia e Estatística. IBGE Cidades: Irati, PR. 2021a. Disponível em: < https://cidades. ibge.gov.br/brasil/pr/irati/panorama > . Acesso em: abr. 2021.

IBGE - Instituto Brasileiro de Geografia e Estatística. Comissão Nacional de Classificação: código de atividades econômicas. 2021b. Disponível em: < https://concla.ibge. gov.br/busca-online-cnae.html? view $=$ subclasse $\&$ tipo $=$ cnae $\&$ versao $=10.1$.0 \& subclasse $=5611201 \&$ chave $=$ Alimenta\%C3\%A7\%C3\%A3o> Acesso em: ago., 2021.

Ibrahim, M.; Mohamed, N. A. E. M. Towards sustainable management of solid waste in Egypt. Procedia Environmental Sciences, 34(1), 336-347, 2016. doi: 10.1016/j. proenv.2016.04.030

IPARDES - Instituto Paranaense de Desenvolvimento Econômico e Social. Caderno estatístico: município de
Irati, 2019. Disponível em: <http://www.ipardes.gov.br/ cadernos/MontaCadPdf1.php?Municipio $=84500>$. Acesso em: abr. 2021.

Irati. Lei n. 4.229, de 30 de dezembro de 2016. Dispõe sobre o código de posturas do município de Irati. Irati: 30/12/2016. Disponível em: $<$ https://leismunicipais.com.br/codigo-de-posturas-irati-pr> Acesso em: ago. 2021.

Jeswani, H. K.; Azapagic, A. Assessing the environmental sustainability of energy recovery from municipal solid waste in the UK. Waste Management, 50(1), 346-363, 2016. doi: 10.1016/j.wasman.2016.02.010

Kaza, S.; Yao, L.; Bhada-Tata, P.; Woerden, F. V. What a Waste 2.0: a global snapshot of solid waste management to 2050. Urban Development. Washington, DC: The World Bank, 2018.

Klarin, T. The concept of sustainable development: from its beginning to the contemporary issues. Zagreb International Review of Economics and Business, 21(1), 67-94, 2018. doi: 10.2478/zireb-2018-0005

Landry, C.; A Smith, T.; Turner, D. Food waste and food retail density. Journal of Food Products Marketing, 24(5), 632-653, 2018. doi: 10.1080/10454446.2018.1472697

Lima, L. C.; Fia, R.; Ribeiro, A. G. C.; Hashizume, B. M.; Soares, R. A. Qualidade do composto gerado no tratamento de resíduos sólidos de restaurante e diferentes resíduos orgânicos. Reveng, 25(5), 407-416, 2017. doi: 10.13083/ reveng.v25i5.812

Lloret, A. Modeling corporate sustainability strategy. Journal of Business Research, 69(2), 418-425, 2016. doi: 10.1016/j.jbusres.2015.06.047

MAPA - Ministério da Agricultura Pecuária e Abastecimento. Instrução Normativa $n^{\circ} 44$, de 2 de outubro de 2007. Brasília: DOU de 03/10/2007.

Nascimento, E. P. Trajetória da sustentabilidade: do ambiental ao social, do social ao econômico. Estudos Avançados, 74(26), 51-64, 2012. doi: 10.1590/S010340142012000100005.

Nidomolu, R.; Prahalad, C. K.; Rangaswami, M. R. Why Sustainability is now the key driver of innovation. Harvard Business Review, (Special Edition), 1-10, 2009. 
Disponível em: https://hbr.org/2009/09/why-sustainability-is-now-the-key-driver-of-innovation

Okwesili, J.; Ndukwe, C.; Nwuzor, C. I. Urban solid waste management and environmental sustainability in Abakaliki Urban, Nigeria. European Scientific Journal, 12(23), 155183, 2016. doi: 10.19044/esj.2016.v12n23p155

Olawumi, T. O.; Chan, D. W. M. A scientometric review of global research on sustainability and sustainable development. Journal of Cleaner Production, 183(1), 231-250, 2018. doi: 10.1016/j.jclepro.2018.02.162

Oliveira, D. P. R. Empresa Familiar: como fortalecer o empreendimento e otimizar o processo sucessório. São Paulo: Atlas, 2006.

Paraná. Lei n. 12.493, de 22 de janeiro de 1999. Curitiba: DOU de 05/02/1999.

Pereira, J. M. Manual de metodologia da pesquisa cientifica. São Paulo: Atlas, 2010.

Peruchin, B.; Guidoni, L. L. C.; Corrêa, L. B.; Corrêa, E. K. Gestão de resíduos sólidos em restaurante escola. Tecnológica, 17(1), 13-23, 2013. doi: 10.17058/tecnolog.v17i1.3627

Pistorello, J.; Conto, S. M.; Zaro, M. Geração de resíduos sólidos em um restaurante de um hotel da Serra Gaúcha, Rio Grande do Sul, Brasil. Engenharia Sanitária e Ambiental, 20(3), 337-346, 2015. doi: 10.1590/S141341522015020000133231.

Potdar, A.; Singh, A.; Unnikrishnan, S.; Naik, N; Naik, M.; Nimkar, I. Innovation in solid waste management through clean development mechanism in developing countries. Procedia Environmental Sciences, 35(1), 193-200, 2016. doi: 10.1016/j.proenv.2016.07.078

Sahu, P. K. Research methodology: a guide for researchers in agricultural science, social science and other relates fields. New York: Springer, 2013.

SEBRAE - Serviço Brasileiro de Apoio às Micro e Pequenas Empresas. Qual a receita bruta e o número de empregados para MEI, ME e EPP?, 2017. Disponível em: <https://blog. sebrae-sc.com.br/numero-de-empregados-receita-bruta-para-mei-me-epp/>. Acesso em: out. 2020.

Thyberg, K. L.; Tonjes, D. J. Drivers of food waste and their implications for sustainable policy development. Resources, Conservation and Recycling, 106(1), 110-123, 2016. doi: 10.1016/j.resconrec.2015.11.016

Vergara, S. C. Métodos de pesquisa em administração. São Paulo: Atlas, 2006.

Voss, B. L.; Pfitscher, E. D.; Rosa, F. S.; Ribeiro, M. S. Evidenciação ambiental dos resíduos sólidos de companhias abertas no Brasil potencialmente poluidoras. Revista Contabilidade \& Finanças, 24(62), 125-141, 2013. doi: 10.1590/ S1519-70772013000200004

Yin, R. K. Estudo de caso: planejamento e métodos. Porto Alegre: Bookman, 2010.

Zollo, M.; Cennamo, C.; Neumann, K. Beyond what and why. Organization \& Environment, 26(3), 241-259, 2013. doi: $10.1177 / 1086026613496433$ 